\title{
BERSCHIN, Walter, GEUENICH, Dieter, STEUER, Heiko, Mission und Christianisierung am Hoch- und Oberrhein (6.-8. Jahrhundert)
}

\section{Charles Mériaux}

\section{(2) OpenEdition \\ Journals}

Édition électronique

URL : http://journals.openedition.org/ifha/1289

DOI : $10.4000 /$ ifha. 1289

ISSN : 2198-8943

Éditeur

IFRA - Institut franco-allemand (sciences historiques et sociales)

Référence électronique

Charles Mériaux, «BERSCHIN, Walter, GEUENICH, Dieter, STEUER, Heiko, Mission und Christianisierung am Hoch- und Oberrhein (6.-8. Jahrhundert) », Revue de l'IFHA [En ligne], Date de recension, mis en ligne le 01 janvier 2000, consulté le 22 septembre 2020. URL : http://journals.openedition.org/ifha/1289 ; DOI : https://doi.org/10.4000/ifha.1289

Ce document a été généré automatiquement le 22 septembre 2020.

(CIFHA 


\title{
BERSCHIN, Walter, GEUENICH, Dieter, STEUER, Heiko, Mission und Christianisierung am Hoch- und Oberrhein (6.-8. Jahrhundert)
}

\author{
Charles Mériaux
}

L'année 1996 a été marquée en France par les célébrations du quinzième centenaire du baptême de Clovis mais l'on sait à quel point la chronologie de l'événement permet mal de retenir une date définitive, qui pourrait tout aussi bien être celle de 508. C'est ainsi qu'en Allemagne, les rencontres scientifiques tenues la même année ont préféré placer au cœur de leurs discussions la bataille de Tolbiac/Zülpich, ce qui contribua à focaliser l'intérêt des chercheurs autour des Alamans et de leur intégration progressive dans le regnum Francorum des VIe-VIIe s. (voir ainsi Dieter Geuenich (dir.), Die Franken und die Alemannen bis zur "Schlacht bei Zülpich (496/7) », Berlin/New-York : de Gruyter (Ergänzungsbände zum Reallexikon der germanischen Altertumskunde, 19), 1998). Les thèmes de conversion et de christianisation ne furent pas pour autant négligés comme en témoigne la parution de ce volume qui dégage l'originalité du processus au regard de ce que l'on sait du reste de la Gaule romanisée. En Alémanie, l'implantation du christianisme est à mettre au double crédit des ducs (et autres aristocrates) et de l'activité itinérante des disciples de l'Irlandais Colomban, puis de leurs successeurs. Il existe désormais des témoignages concrets : les recherches archéologiques multiplient les découvertes d'églises (H. W. BÖHME ; B. SCHOLKMANN, avec un catalogue de 105 églises) que l'on rapproche des nombreuses Eigenkirchen (églises privées) passées au VIIIe s. dans la main des grands monastères, essentiellement Saint-Gall et Reichenau. Ce sont d'ailleurs les possessions de ces grands établissements qui dessinèrent progressivement les contours du diocèse de Constance. L'occasion est ainsi donnée à $H$. MAURER de rappeler à quel point l'institution épiscopale est restée en marge du processus d'évangélisation : en 724, l'activité du missionnaire Pirmin semble ignorer toute autorité épiscopale dans la région et par la suite (de 736 à 782) la charge est occupée par les abbés de Reichenau, qui, avec Saint-Gall, se présente comme le 
véritable centre religieux du diocèse. Cette confusion est en définitive assez classique et une comparaison peut s'avérer très éclairante avec d'autres marges du monde franc, septentrionales (diocèse de Thérouanne au VIIe s., missions de Willibrord en Frise à l'aube du VIIIe s.) et orientales (Boniface en Germanie dans le courant du VIIIe s., christianisation de la Saxe au IXe s.). Le volume est complété par des contributions concernant le monastère de Säckingen (A. ZETTLER ; F. SCHMAEDECKE, pour les aspects archéologiques) et des traditions tardives relatives à sa fondation par saint Fridolin, dont la Vie (Xe s.) évoque la rencontre - imaginaire, de toute évidence - avec Clovis (on consultera désormais l'édition de Mechtild Pörnbacher, Vita sancti Fridolini. Leben und Wunder des heiligen Fridolin von Säckingen beschrieben von Balther von Säckingen, Bischof von Speyer. Texte - Übersetzung - Kommentar, Sigmaringen : Thorbecke, 1997) ; elle fournit ainsi la matière d'une communication de G. SANDER sur le topos hagiographique des relations entre missionnaire et souverain. Enfin, le lecteur pourrait s'étonner de trouver dans le volume un exposé (K.S. FRANCK) consacré à Hilaire, évêque de Poitiers († 367/368). Celui-ci est rapidement devenu le patron spirituel du monastère de Säckingen (Fridolin y aurait apporté ses reliques) et il était donc juste de réserver une petite place à cette figure marquante de l'épiscopat gaulois à l'occasion du colloque, organisé à Bad Säckingen même du 7 au 9 mars 1997. 